\begin{tabular}{|c|l|}
\hline Title & A population of BJ fibroblasts escaped from Ras induced senescence susceptible to transformation \\
\hline Author(s) & $\begin{array}{l}\text { Kohsaka, Shinji; Sasai, Ken; Takahashi, Kenta; A kagi, Tsuyoshi; Tanino, Mishie; Kimura, Taichi; Nishihara, Hiroshi; } \\
\text { Tanaka, Shinya }\end{array}$ \\
\hline Citation & $\begin{array}{l}\text { Biochemical and Biophysical Research Communications, 410(4), 878-884 } \\
\text { https://doi.org/10.1016j.bbrc.2011.06.082 }\end{array}$ \\
\hline Issue Date & 2011-07-15 \\
\hline Doc URL & http://hdl.handle.net/2115/46956 \\
\hline Type & article(author version) \\
\hline File Information & BBRC410-4_878-884.pdf \\
\hline
\end{tabular}

Instructions for use 


\section{A population of BJ fibroblasts escaped from Ras-induced senescence susceptible to transformation}

Shinji Kohsaka ${ }^{1}$, Ken Sasai ${ }^{1,4}$, Kenta Takahashi ${ }^{1}$, Tsuyoshi Akagi ${ }^{2}$, Mishie Tanino ${ }^{1}$, Taichi Kimura $^{1}$, Hiroshi Nishihara ${ }^{3}$, Shinya Tanaka*1,3

${ }^{1}$ Laboratory of Cancer Research, Department of Pathology, Hokkaido University Graduate School of Medicine, N15, W7, Kita-ku, Sapporo 060-8638, Japan, ${ }^{2}$ KAN Research Institute Inc., Kobe MI R\&D Center, 6-7-3 Minatojima-minamimachi, Chuo-ku, Kobe, 650-0047, Japan, ${ }^{3}$ Department of Translational Pathology, Hokkaido University Graduate School of Medicine, N15, W7, Kita-ku, Sapporo 060-8638, Japan.

${ }^{4}$ Present address: KAN Research Institute Inc., Kobe MI R\&D Center, 6-7-3

Minatojima-minamimachi, Chuo-ku, Kobe, 650-0047, Japan

Corresponding author: Shinya Tanaka, M.D., Ph.D.

Laboratory of Cancer Research, Department of Pathology,

Hokkaido University Graduate School of Medicine

N15, W7, Kita-ku, Sapporo, 060-8638, Japan.

Tel.: +81-11-706-5052 Fax: +81-11-706-5902

e-mail: tanaka@med.hokudai.ac.jp

Key words: oncogene-induced senescence; Ras; p16; p53; stem cell 


\begin{abstract}
Oncogenic stimuli such as H-Ras induce oncogene-induced senescence (OIS) in fibroblasts to protect against transformation. Here we found that a population of the human diploid fibroblasts can escape from OIS induced by H-RasV12. We designated these OIS-escaped cells as OISEC (OIS-escaped cells). OISEC lost the expression of p16 which plays an important role for cell cycle arrest for induction of senescence, but OISEC preserved the p16 expression machinery and exhibited senescence by the treatment with hydrogen peroxide $\left(\mathrm{H}_{2} \mathrm{O}_{2}\right)$ as stress-induced premature senescence (SIPS). OISEC did not possess anchorage-independent growth potential, and functional disruption of p53 and Rb by SV40 early region encoding large $\mathrm{T}$ and small $\mathrm{t}$ antigens, induced the aneuploidy phenotype and colony-forming potential of OISEC together with the exhibition of in vivo tumor formation. Finally, we also found that the distinctive feature of OISEC is expression of transcription factors, Oct3/4, SOX2, and Nanog which is closely related to stem-like cell features. This study highlights the presence of a cell population which escaped from OIS, and this OISEC may transform into malignant cancer cells by the additional hits of several genes in vivo.
\end{abstract}




\section{Introduction}

Cellular senescence was originally defined as a permanent state of cell cycle arrest that was observed when primary human diploid fibroblasts (HDFs) reached their limit of duplication [1]. This type of senescence, termed replicative senescence, is caused by the shortening of a telomere, which is a protective structure capping the end of eukaryotic chromosomes [2].

Cellular senescence was found to be induced by oncogenic stress such as Ras [3], giving rise to the term oncogene-induced senescence (OIS). Currently OIS is known to be induced by various kinds of oncogenic stimulation [4]. Subsequently, cell cycle arrest by p16 has been shown to be one of the important mechanisms for OIS, regulated by combination of Ets and Id1 [5]. p16 downregulation is able to prevent RAS-induced senescence $[5 ; 6 ; 7]$, and p16 determines the sensitivity of HDFs to transformation by cooperating oncogenes [8]. In addition, the representative tumor suppressors such as p53 and $\mathrm{Rb}$ are also known to be involved in OIS without critical telomere attrition $[9 ; 10 ; 11]$. Several recent studies have shown that OIS provides an initial barrier to tumorigenesis in vivo $[12 ; 13 ; 14]$.

While OIS is thought to play an important role in suppressing tumorigenesis by preventing proliferation of cells $[15 ; 16]$, it has also been reported that low-level induction of Ras cannot induce OIS in vitro and in vivo $[17 ; 18]$. Thus the decision of cells to undergo senescence or proliferation in response to Ras may partially depend upon the levels of Ras activation [18]. However, the precise mechanism of the threshold of Ras-dependent OIS is still unknown.

It has recently been reported that disruption of the p53 pathway enhances the production of induced pluripotent stem (iPS) cells, and that Ink4a/Arf locus is silenced during iPS reprogramming $[19 ; 20 ; 21 ; 22]$. These reports demonstrated that p53 and p16 also regulate the stemness of cells, as several transcription factors, including Oct3/4 [23], Sox2 
[24], and Nanog [25], maintain the pluripotency in ES cells.

In this study, we demonstrated that a certain population of cells did not undergo OIS in response to ectopic expression of H-RasV12 in human diploid fibroblasts. These cells are designated as OISEC (oncogene-induced senescence escaped cells). We found that OISEC preserved the potential for being induced to the senescence state, and do not possess anchorage-independent growth potential. Furthermore, OISEC can be transformed by SV40ER which disrupts $\mathrm{p} 53$ and $\mathrm{Rb}$. We found that OISEC exhibit the expression of mRNA of transcription factors which are closely related to the stemness of the cells. OISEC escape cell may provide an important aspect of the initiation of cancer in vivo. 


\section{Materials and Methods}

\subsection{Cells}

Human telomerase catalytic subunit (hTERT)-expressing BJ cells, human diploid foreskin fibroblasts (American Type Culture Collection \#CCL-2522), were established and maintained as described previously [26].

\subsection{Retroviral vectors}

pCX4 vectors with different drug-selection markers were constructed previously [26]. An activated mutant of human $\mathrm{H}-\mathrm{Ras}, \mathrm{H}-\mathrm{RasV} 12$, in $\mathrm{pCX} 4 \mathrm{pur}$, the human telomerase catalytic subunit (hTERT) into pCX4neo and the SV40 ER in pCX4bsr were described previously [26]. p16 in pCX4bsr was kindly provided by Dr. Masataka Sugimoto (National Center for Geriatrics and gerontology, Aichi, Japan). H-RasV12 was subcloned into pCX4bleo.

\subsection{Soft-agar colony formation assay and xenograft propagation Colony formation} assay was performed by the standard protocol described elsewhere. $5 \times 10^{4}$ cells were used as initial plating number. For xenograft preparation, $5 \times 10^{6}$ cells were injected s.c. into 6 - to 8-week-old female athymic nude mice (BALB/cAJcl-nu/nu),

2.4. Senescence-associated $\boldsymbol{\beta}$-galactosidase (SA- $\boldsymbol{\beta}$-gal) detection $1 \times 10^{5}$ cells were plated into 35-mm dishes. Cells were washed once with PBS. At the indicated times, cells were washed with PBS, fixed and stained for $\beta$-galactosidase using the Senescence Detection Kit (BioVision, Mountain View, CA, USA).

\subsection{Induction of stress-induced premature senescence}

$1 \times 10^{4}$ cells were plated in $60-\mathrm{mm}$ dishes and exposed to $500 \mu \mathrm{M} \mathrm{H}_{2} \mathrm{O}_{2}$ for $2 \mathrm{~h}$ at $37^{\circ} \mathrm{C}$. All cells were then washed twice with PBS and cultured in DMEM supplemented with $10 \%$ FBS. 


\subsection{Ploidy analysis with FACS.}

Cells were fixed by ice-cold 70\% ethanol, and cell pellets were resuspended, and DNA content was labeled by a $0.5-\mathrm{ml}$ solution of propidium iodide at $20 \mu \mathrm{g} / \mathrm{ml}$ in PBS, containing RNase at a final concentration of $200 \mu \mathrm{g} / \mathrm{ml}$. Samples were stained at room temperature for 30 min and analyzed on a FACS Calibur (BD Biosciences, Mountain View, CA, USA).

\subsection{Immunoblotting.}

SDS-PAGE was performed by the standard protocol described elsewhere. Filters were probed with mouse monoclonal antibodies to p21WAF1 (Ab-1; Calbiochem, San Diego, CA, USA), RAS (Transduction Laboratories, Lexington, KY, USA), p53 (Cell Signaling Technology, Beverly, MA, USA), phospho-Histone H2A.X (Ser139)(Millipore, Temecula, CA, USA) and Actin (Chemicon, Temecula, CA, USA), or rabbit polyclonal antibodies to p16 (H156; Santa Cruz Biotechnology, Santa Cruz, CA, USA), Ets-2 (Santa Cruz Biotechnology, Santa Cruz, CA, USA) and phospho-ERK (Cell Signaling Technology, Beverly, MA, USA).

\subsection{Reverse Transcription-PCR Analysis.}

RT-PCR was performed by the standard protocol described elsewhere. Sequences of the primer sets are as follows: 5'-TGC AAA TGT CTT CTG CTG AGA T-3`' (sense) and 5'-GTT CAG GAT GTT GGA GAG TTC-3‘ (antisense) for Nanog, 5’-CGA CCA TCT GCC GCT TTG AG-3‘ (sense) and 5'-CCC CCT GTC CCC CAT TCC TA-3‘ (antisense) for Oct3/4, 5 '-AGT CTC CAA GCG ACG AAA AA-3‘ (sense) and 5'-GGA AAG TTG GGA TCG AAC AA-3‘ (antisense) for Sox2, 5 '-CTCATGACCACAGTCCATGC-3' (sense) and 5'-TTA CTC CTT GGA GGC CAT GT-3‘ (antisense) for glyceraldehyde-3-phosphate dehydrogenase (GAPDH). 


\section{Results}

\subsection{Escape from Ras-induced senescence in human fibroblasts}

To investigate the mechanism of oncogene-induced senescence, we utilized BJ cells and introduced H-RasV12 by retroviral vector. To avoid replicative senescence, human telomerase catalytic subunit (hTERT) was expressed prior to H-RasV12 introduction. The morphology of hTERT introduced BJ cells is spindle, and 10 days after H-RasV12 introduction, BJ cells exhibited flatness and enlargement, suggesting a senescence feature. These cells were also found to be positive for SA- $\beta$-gal (Fig. 1A).

Two weeks after H-RasV12 introduction, the focus of proliferation of the spindle cells could be observed, and the proportion of these cells became dominant over the flat cells in senescence (Fig. 1A). These proliferating spindle cells were designated as oncogene-induced senescence escaped cells (OISEC). By using time-lapse microscopy, we confirmed that senescent cells did not show reversal into the spindle shape and proliferate again (data not shown).

To analyze the mechanism how OISEC could escape from OIS, we examined the expression level of several cell-cycle regulatory proteins by immunoblotting (Fig. 1B), and found that the level of p16 was dramatically low (more than 10-fold) in OISEC compared to that in OIS cells. The levels of Ras, phospho-ERK, Ets-2, p53, and p21 were constant between OIS cells and OISEC. We also found that $\gamma$-H2AX, a DNA double strand break marker, is positive only in OIS cells.

\subsection{Re-induction of senescence in OISEC by H-RasV12, p16 or stress stimuli}

To investigate whether OISEC preserved the potential of exhibiting senescence, we examined the effect of forced expression of p16 on OISEC, and found the induction of senescence when we introduced p16 (Fig. 2A). As we investigated the methylation status in the promoter regions of the p16 using bisulfite sequencing and observed no alteration in 
OISEC when compared to OIS cells (data not shown), there may be a defect in the Ras-dependent p16 expression mechanism. As the threshold of Ras to induce senescence seems to be increased in OISEC, we examined the effect of further re-expression of Ras on OISEC, and found re-expression of p16 and re-induction of senescence (Fig. 2B).

Cells subjected to certain types of sublethal stress also enter a state resembling replicative senescence which is termed stress-induced premature senescence (SIPS) [27]. SIPS can be induced by stressful conditions such as ultraviolet or $\mathrm{H}_{2} \mathrm{O}_{2}$ treatment. The molecular mechanism of SIPS induction is thought to be accumulation of p53, p21 and p16 accompanied with DNA damage. To elucidate whether OISEC preserved the potential to undergo SIPS, we examined the sensitivity of OISEC to the $\mathrm{H}_{2} \mathrm{O}_{2}$ treatment. Cell growth of OISEC was stopped by $\mathrm{H}_{2} \mathrm{O}_{2}$ treatment and flattened cells were positive for SA- $\beta$-gal (Fig. 2C). The p16 expression was also induced by $\mathrm{H}_{2} \mathrm{O}_{2}$ in OISEC (Fig. 2C). These results suggest that OISEC have an intact mechanism of p16-dependent cell cycle arrest.

\subsection{Induction of anchorage-independent growth and in vivo tumor formation in OISEC by SV40 early region}

To investigate whether OISEC have a transforming potential, we examined the ability for anchorage-independent growth by soft-agar colony formation assay, but OISEC failed to make any colonies (Fig. 3A). It has been well documented that the combination of hTERT, SV40ER, and H-RasV12 is sufficient for transformation [28; 29]; therefore, we introduced SV40 early region (ER), which disrupts p53 and Rb function, into OISEC which had already expressed both hTERT and RasV12, and then colony formation was observed (Fig. 3A). After introduction of SV40ER, we confirmed the expression of p16 and p53 (Fig.

3D). OISEC introduced by SV40ER was also found to make tumors in nude mice (Fig. 3B). It should be noted that the colony number and tumor size in vivo of OISEC with SV40ER were smaller than those in BJ cells expressing hTERT, H-RasV12 and SV40ER, and that 
tumor formation was observed less frequently in OISEC with SV40ER than in BJ cells expressing hTERT, H-RasV12 and SV40ER (Fig. 3C).

\subsection{Transformation of OISEC is accompanied by genomic instability}

It is now widely accepted that a number of cancers are genetically unstable. Especially, chromosomal instability (CIN) contributes to aneuploidy and plays a critical role in tumorigenesis $[30 ; 31 ; 32]$. We evaluated CIN in OISEC by analyzing the cellular DNA content using a flow cytometry and by fluorescence in situ hybridization (FISH) analysis. It has been reported that BJ cells expressing hTERT, H-RasV12, and SV40ER are highly aneuploid [26]. As shown in Fig. 4A, OISEC expressing SV40ER were highly aneuploid, whereas most of OISEC or BJ expressing hTERT and SV40ER remained diploid. We also analyzed the DNA content of xenograft originating from OISEC expressing SV40ER and found that the proportion of aneuploid cells of xenograft was much larger than that of cultured cells. For confirmation of the alteration of ploidy, we employed FISH analysis with probe 1q44, which can represent the copy number of chromosome 1 [33]. About 75\% of OISEC had two signals, but introduction of SV40ER in OISEC increased the number of cells having more than three signals (Fig. 4B). This result indicate that the tumorigenicity of OISEC with SV40ER is related to its higher population of genetically unstable cells.

\subsection{OISEC are positive for Oct3/4, SOX2 and Nanog}

Because recently p53 or p16 has been shown to be involved in the maintenance of stem cell population, we hypothesized that OISEC might be a stem cell population, and investigated the expression levels of Oct3/4, SOX2, and Nanog by RT-PCR. OISEC were positive for all of these mRNA expressions, while only clear expression of Nanog was found in OIS cells (Fig. 4C). 


\section{Discussion}

OIS provides an initial barrier to tumorigenesis in vivo, as preneoplastic lesions contain a lot of cells indicating senescence markers $[12 ; 13 ; 14]$. Thus, overcoming OIS is an essential step in malignant transformation. We found that a population of BJ cells can escape from OIS induced by the expression of H-RasV12 (Fig. 4D). The same phenomenon can be observed in other HDFs cell lines, IMR-90 and TIG-3 (data not shown). As a number of studies have shown that p16 or p21 play an important role in OIS, we clearly showed that escaped cells from OIS lost p16 expression. Initially, we speculated that the epigenetic methylation of p16 promoter was dominant in OISEC, but methylation-specific PCR analysis did not reveal significant methylation of p16 promoter (data not shown). In fact, preservation of $\mathrm{p} 16$ expression mechanism in OISEC could be proved by the treatment of OISEC by $\mathrm{H}_{2} \mathrm{O}_{2}$ as premature senescence. Furthermore, re-introduction of H-Rasv12 inducing senescence in OISEC (Fig. 4D) indicated that the threshold of Ras for senescence was elevated in OISEC. As Ras-induced senescence is regulated by p16 expression depending on Ets family transcription factors which can be negatively regulated by Id1, the regulatory machinery for p16 by Ets and Id 1 may be disrupted in OISEC. In OISEC, expression levels of p53 and p21 were constant compared to OIS cells; thus, p53 may be intact in OISEC.

In various cancers including colon cancer, it has been reported that K-Ras mutation usually occurs for adenoma lesion and subsequent p53 mutation occurs later and works as an essential step for transformation to carcinoma [34]. Thus, one can speculate that when the initial mutation of Ras occurs in vivo, the majority of cells undergo senescence, and a rare population of OISEC continues to proliferate, and subsequent mutation of p53 leads cells to the direction of transformation. In fact, BJ cell-based OISEC did not possess anchorage-independent growth potential, but disruption of p53 and Rb by SV40ER clearly led to transforming potential (Fig. 4D). Furthermore, since we confirmed that OISEC made no 
tumor by additional introduction of the dominant negative form of p53 or CDK4 which inhibits $\mathrm{Rb}$ function, disruption of both of $\mathrm{p} 53$ and $\mathrm{Rb}$ may be required for transformation of OISEC.

Considering that transformed OISEC exhibited aneuploidy, both p53 and Rb prevented cells from becoming aneuploid. Currently, it has been suggested that extra centrosomes promote chromosome missegregation and generate $\mathrm{CIN}$ by promoting merotelic kinetochore-microtubule attachments [35]. Thus, an intriguing question is whether we can observe extra centrosomes and chromosome missegregation in OISEC.

In this study, we found that OISEC express several transcription factors which are closely related to exhibiting stem cell features of cells such as Nanog, Oct3/4, and Sox2. These results suggest that OIS-resistant cells possess possible stem cell-like features. On the other hand, it is reasonable that stem cells are resistant to oncogenic stimuli and protected from DNA damages, and they can easily escape from OIS. Considering that repressing the Ink4a/Arf locus genes, p16 and p19, by the polycomb group protein Bmi-1 regulates self-renewal and proliferation of hematopoietic and neural stem cells [36; 37], p16 repression in OISEC can be thought of as another stem-like cell feature of OISEC.

In this study, we found that OIS can be escaped by a population of cells, possibly a stem cell population, but OISEC are not transformed because their p16 and p53 pathways still work as an anti-cancer mechanism eliminating OISEC if they accumulate DNA damage or become aneuploid. Still, we need to unveil the precise mechanism regarding how OISEC can get the resistance with inappropriate response of p16 pathway, where in human tissue these OISEC exist, and whether they possess stem cells feature.

(END) 


\section{Acknowledgments}

We thank Ms. Mami Sato and Dr. Masahisa Tsuji (Chromosome Science Labo Inc., Japan) for FISH analysis. Also, we thank Dr. Masataka Sugimoto (Research Institute, National Center for Geriatrics and Gerontology, Japan) for providing the plasmid. This study was supported in part by Grants-in-Aid from the Ministry of Education, Science, Culture, and Sports, Japan. 


\section{References}

[1] L. Hayflick, The Limited in Vitro Lifetime of Human Diploid Cell Strains. Exp Cell Res 37 (1965) 614-36.

[2] Y. Deng, S.S. Chan, and S. Chang, Telomere dysfunction and tumour suppression: the senescence connection. Nat Rev Cancer 8 (2008) 450-8.

[3] M. Serrano, A.W. Lin, M.E. McCurrach, D. Beach, and S.W. Lowe, Oncogenic ras provokes premature cell senescence associated with accumulation of p53 and p16INK4a. Cell 88 (1997) 593-602.

[4] M. Tsuda, T. Watanabe, T. Seki, T. Kimura, H. Sawa, A. Minami, T. Akagi, K. Isobe, K. Nagashima, and S. Tanaka, Induction of p21(WAF1/CIP1) by human synovial sarcoma-associated chimeric oncoprotein SYT-SSX1. Oncogene 24 (2005) 7984-90.

[5] N. Ohtani, Z. Zebedee, T.J. Huot, J.A. Stinson, M. Sugimoto, Y. Ohashi, A.D. Sharrocks, G. Peters, and E. Hara, Opposing effects of Ets and Id proteins on p16INK4a expression during cellular senescence. Nature 409 (2001) 1067-70.

[6] S. Brookes, J. Rowe, M. Ruas, S. Llanos, P.A. Clark, M. Lomax, M.C. James, R. Vatcheva, S. Bates, K.H. Vousden, D. Parry, N. Gruis, N. Smit, W. Bergman, and G. Peters, INK4a-deficient human diploid fibroblasts are resistant to RAS-induced senescence. Embo J 21 (2002) 2936-45.

[7] T.J. Huot, J. Rowe, M. Harland, S. Drayton, S. Brookes, C. Gooptu, P. Purkis, M. Fried, V. Bataille, E. Hara, J. Newton-Bishop, and G. Peters, Biallelic mutations in p16(INK4a) confer resistance to Ras- and Ets-induced senescence in human diploid fibroblasts. Mol Cell Biol 22 (2002) 8135-43.

[8] S. Drayton, J. Rowe, R. Jones, R. Vatcheva, D. Cuthbert-Heavens, J. Marshall, M. Fried, and G. Peters, Tumor suppressor p16INK4a determines sensitivity of human cells to transformation by cooperating cellular oncogenes. Cancer Cell 4 (2003) 301-10.

[9] R. Di Micco, M. Fumagalli, A. Cicalese, S. Piccinin, P. Gasparini, C. Luise, C. Schurra, M. 
Garre, P.G. Nuciforo, A. Bensimon, R. Maestro, P.G. Pelicci, and F. d'Adda di Fagagna, Oncogene-induced senescence is a DNA damage response triggered by DNA hyper-replication. Nature 444 (2006) 638-42.

[10] J. Bartkova, N. Rezaei, M. Liontos, P. Karakaidos, D. Kletsas, N. Issaeva, L.V. Vassiliou, E. Kolettas, K. Niforou, V.C. Zoumpourlis, M. Takaoka, H. Nakagawa, F. Tort, K. Fugger, F. Johansson, M. Sehested, C.L. Andersen, L. Dyrskjot, T. Orntoft, J. Lukas, C. Kittas, T. Helleday, T.D. Halazonetis, J. Bartek, and V.G. Gorgoulis, Oncogene-induced senescence is part of the tumorigenesis barrier imposed by DNA damage checkpoints. Nature 444 (2006) 633-7.

[11] M. Narita, S. Nunez, E. Heard, M. Narita, A.W. Lin, S.A. Hearn, D.L. Spector, G.J. Hannon, and S.W. Lowe, Rb-mediated heterochromatin formation and silencing of E2F target genes during cellular senescence. Cell 113 (2003) 703-16.

[12] C. Michaloglou, L.C. Vredeveld, M.S. Soengas, C. Denoyelle, T. Kuilman, C.M. van der Horst, D.M. Majoor, J.W. Shay, W.J. Mooi, and D.S. Peeper, BRAFE600-associated senescence-like cell cycle arrest of human naevi. Nature 436 (2005) 720-4.

[13] M. Collado, J. Gil, A. Efeyan, C. Guerra, A.J. Schuhmacher, M. Barradas, A. Benguria, A. Zaballos, J.M. Flores, M. Barbacid, D. Beach, and M. Serrano, Tumour biology: senescence in premalignant tumours. Nature 436 (2005) 642.

[14] M. Braig, S. Lee, C. Loddenkemper, C. Rudolph, A.H. Peters, B. Schlegelberger, H. Stein, B. Dorken, T. Jenuwein, and C.A. Schmitt, Oncogene-induced senescence as an initial barrier in lymphoma development. Nature 436 (2005) 660-5.

[15] J. Campisi, and F. d'Adda di Fagagna, Cellular senescence: when bad things happen to good cells. Nat Rev Mol Cell Biol 8 (2007) 729-40.

[16] M. Collado, M.A. Blasco, and M. Serrano, Cellular senescence in cancer and aging. Cell 130 (2007) 223-33.

[17] Q. Deng, R. Liao, B.L. Wu, and P. Sun, High intensity ras signaling induces premature 
senescence by activating p38 pathway in primary human fibroblasts. J Biol Chem 279 (2004) 1050-9.

[18] C.J. Sarkisian, B.A. Keister, D.B. Stairs, R.B. Boxer, S.E. Moody, and L.A. Chodosh, Dose-dependent oncogene-induced senescence in vivo and its evasion during mammary tumorigenesis. Nat Cell Biol 9 (2007) 493-505.

[19] T. Kawamura, J. Suzuki, Y.V. Wang, S. Menendez, L.B. Morera, A. Raya, G.M. Wahl, and J.C. Belmonte, Linking the p53 tumour suppressor pathway to somatic cell reprogramming. Nature 460 (2009) 1140-4.

[20] H. Li, M. Collado, A. Villasante, K. Strati, S. Ortega, M. Canamero, M.A. Blasco, and M. Serrano, The Ink4/Arf locus is a barrier for iPS cell reprogramming. Nature 460 (2009) $1136-9$.

[21] R.M. Marion, K. Strati, H. Li, M. Murga, R. Blanco, S. Ortega, O. Fernandez-Capetillo, M. Serrano, and M.A. Blasco, A p53-mediated DNA damage response limits reprogramming to ensure iPS cell genomic integrity. Nature 460 (2009) 1149-53.

[22] H. Hong, K. Takahashi, T. Ichisaka, T. Aoi, O. Kanagawa, M. Nakagawa, K. Okita, and S. Yamanaka, Suppression of induced pluripotent stem cell generation by the p53-p21 pathway. Nature 460 (2009) 1132-5.

[23] H. Niwa, J. Miyazaki, and A.G. Smith, Quantitative expression of Oct-3/4 defines differentiation, dedifferentiation or self-renewal of ES cells. Nat Genet 24 (2000) 372-6.

[24] A.A. Avilion, S.K. Nicolis, L.H. Pevny, L. Perez, N. Vivian, and R. Lovell-Badge, Multipotent cell lineages in early mouse development depend on SOX2 function. Genes Dev 17 (2003) 126-40.

[25] K. Mitsui, Y. Tokuzawa, H. Itoh, K. Segawa, M. Murakami, K. Takahashi, M. Maruyama, M. Maeda, and S. Yamanaka, The homeoprotein Nanog is required for maintenance of pluripotency in mouse epiblast and ES cells. Cell 113 (2003) 631-42.

[26] T. Akagi, K. Sasai, and H. Hanafusa, Refractory nature of normal human diploid 
fibroblasts with respect to oncogene-mediated transformation. Proc Natl Acad Sci U S A 100 (2003) 13567-72.

[27] K. Naka, A. Tachibana, K. Ikeda, and N. Motoyama, Stress-induced premature senescence in hTERT-expressing ataxia telangiectasia fibroblasts. J Biol Chem 279 (2004) 2030-7.

[28] W.C. Hahn, and R.A. Weinberg, Modelling the molecular circuitry of cancer. Nat Rev Cancer 2 (2002) 331-41.

[29] W.C. Hahn, C.M. Counter, A.S. Lundberg, R.L. Beijersbergen, M.W. Brooks, and R.A. Weinberg, Creation of human tumour cells with defined genetic elements. Nature 400 (1999) 464-8.

[30] H. Rajagopalan, and C. Lengauer, Aneuploidy and cancer. Nature 432 (2004) 338-41.

[31] A.J. Holland, and D.W. Cleveland, Boveri revisited: chromosomal instability, aneuploidy and tumorigenesis. Nat Rev Mol Cell Biol 10 (2009) 478-87.

[32] G.J. Kops, B.A. Weaver, and D.W. Cleveland, On the road to cancer: aneuploidy and the mitotic checkpoint. Nat Rev Cancer 5 (2005) 773-85.

[33] C.E. Fuller, R.E. Schmidt, K.A. Roth, P.C. Burger, B.W. Scheithauer, R. Banerjee, K. Trinkaus, R. Lytle, and A. Perry, Clinical utility of fluorescence in situ hybridization (FISH) in morphologically ambiguous gliomas with hybrid oligodendroglial/astrocytic features. J Neuropathol Exp Neurol 62 (2003) 1118-28.

[34] W.M. Grady, and J.M. Carethers, Genomic and epigenetic instability in colorectal cancer pathogenesis. Gastroenterology 135 (2008) 1079-99.

[35] N.J. Ganem, S.A. Godinho, and D. Pellman, A mechanism linking extra centrosomes to chromosomal instability. Nature 460 (2009) 278-82.

[36] I.K. Park, D. Qian, M. Kiel, M.W. Becker, M. Pihalja, I.L. Weissman, S.J. Morrison, and M.F. Clarke, Bmi-1 is required for maintenance of adult self-renewing haematopoietic stem cells. Nature 423 (2003) 302-5. 
[37] A.V. Molofsky, R. Pardal, T. Iwashita, I.K. Park, M.F. Clarke, and S.J. Morrison, Bmi-1 dependence distinguishes neural stem cell self-renewal from progenitor proliferation. Nature 425 (2003) 962-7. 


\section{Figure 1}

\section{Escape from Ras-induced senescence in human fibroblasts}

(A) Phase contrast microscopical finding of cultured BJ cells. a. hTERT introduced BJ cells (cont) morphology immediately after infection of retroviral vector expressing H-RasV12 (day0). b. cells morphology at day 10 . c. cells stained with SA- $\beta-$ Gal at day $10 . \quad$ d. cells morphology at day 14. Arrows indicate flat and enlarged cells; arrowheads indicate spindle cells. Magnification is $\times 40$. (B) Immunoblotting of senescence-related proteins in hTERT introduced cells (cont), OIS cells (OIS), and OISEC. Duration after infection of H-RasV12 is indicated at the top as 0 day, 10 days, and 20 days after infection. Examined proteins are indicated at the left of the panel. Actin is shown as a loading control.

\section{Figure 2}

\section{Re-induction of senescence in OISEC by H-RasV12, p16 or stress stimuli}

(A) Phase contrast microscopical finding of cultured BJ cells. a. OISEC. b. H-RasV12 re-introduced OISEC c. p16 introduced OISEC. Magnification is $\times 40$. Immunoblotting of Ras and p16 in OISEC and senescence re-induced OISEC. Total cell lysates were prepared from hTERT introduced cells (cont), OIS cells (OIS), or OISEC with indicated genes. (C) The upper graph shows the growth curves of hTERT introduced cells (cont) (open squares) and OISEC (filled squares) after $\mathrm{H}_{2} \mathrm{O}_{2}$ treatment. Cell numbers were counted every day, and results are expressed as means $\pm \mathrm{SD}$ of three independent experiments $(*, p<0.01$ vs. OISEC). The lower figure shows the protein levels of p16 by immunoblotting following $\mathrm{H}_{2} \mathrm{O}_{2}$ treatment.

\section{Figure 3}

Induction of anchorage-independent growth and in vivo tumor formation in OISEC by SV40 early region 
(A) Soft agar colony formation. a. hTERT introduced BJ cells (cont). b. OISEC. c. SV40ER introduced control cells. d. SV40ER introduced OISEC. e. H-RasV12 and SV40ER introduced control cells. (B) Tumor formation assay in nude mice. Xenografts two months (left) or four months (right) after injection are shown. Arrows indicate tumor masses. (C) Results of colony formation assay and in vivo tumor formation assay. Bar graph represents the number of colonies indicated in (A). Values are mean $\pm \mathrm{SD}$ for triplicates within one experiment $(*, p<0.01$ vs. OISEC+SV40ER; $\uparrow, p=0.001$ vs. cont + SV40ER). The table shows the number of subcutaneous tumors arising per number of injections within the indicated months, as combined from several different experiments. Immunoblotting of senescence-related proteins. Total cell lysates were prepared from hTERT introduced cells (cont), OIS cells (OIS), or OISEC with indicated genes. Analyzed proteins are indicated at the left.

\section{Figure 4}

\section{Transformation of OISEC is accompanied by genomic instability}

(A) Flow cytometric analysis of DNA content in BJ cells. Normal human diploid fibroblasts, BJ population doubling 38 (PD38), or hTERT introduced cells (cont) or OISEC with indicated genes were analyzed for DNA content by using a flow cytometer. Arrows indicate the location of $2 \mathrm{~N}$ and $4 \mathrm{~N}$ peaks as determined by using BJ PD38, where $\mathrm{N}$ represents the haploid genome. (B) BJ cells were hybridized with probes for chromosome 1 (red). The percentage of copy numbers of chromosome 1 in control cells or OISEC introduced with the indicated genes are shown. Representative examples of BJ cells hybridized with single to quintuple probe for chromosome 1 are shown. (C) RT-PCR analysis of Oct3/4, SOX2, and Nanog in OISEC. hTERT introduced BJ cells (cont), BJ OIS cells (OIS), or BJ OISEC with indicated genes were analyzed for mRNA expression level of Oct3/4, Sox 2 and Nanog by semi-quantitative RT-PCR. GAPDH is shown as a loading control. (D) Scheme of 
multistep tumorigenesis. While most cells induce OIS against oncogenic stress, a population of stem-like cells can escape from OIS and wait for the next hit which will disrupt the p53 and p16 pathway and lead to transformation. 
Fig. 1

A
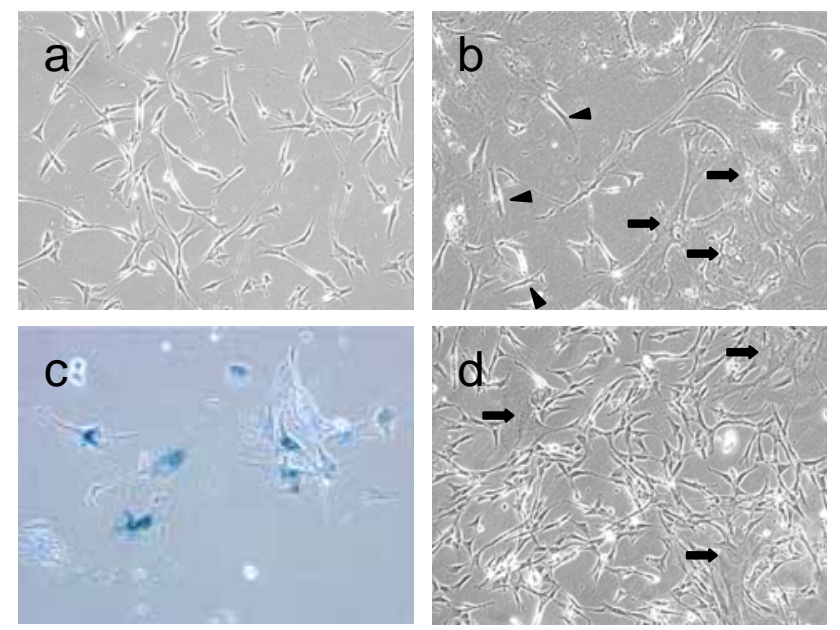

B

\section{BJ}

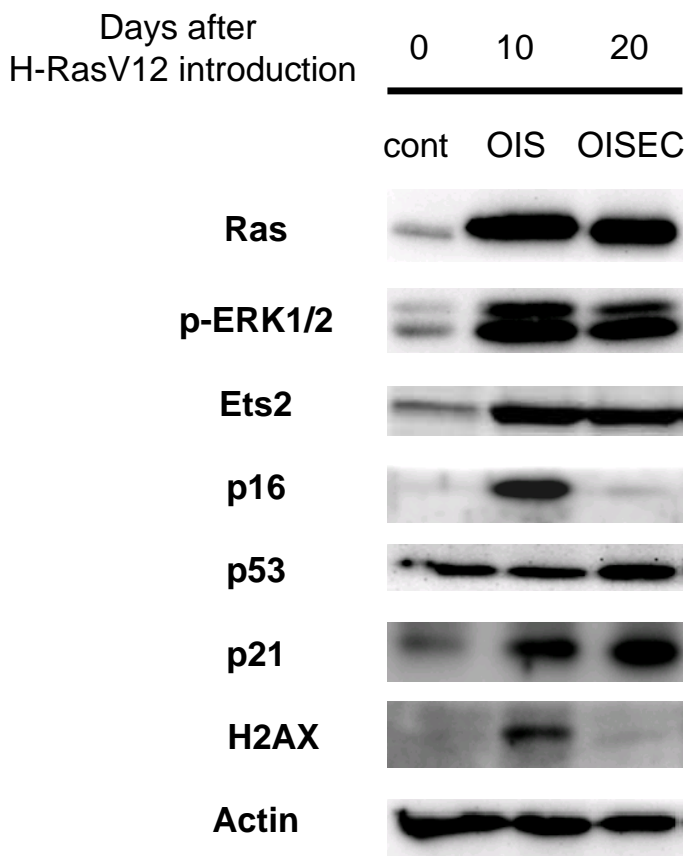


Fig. 2

A
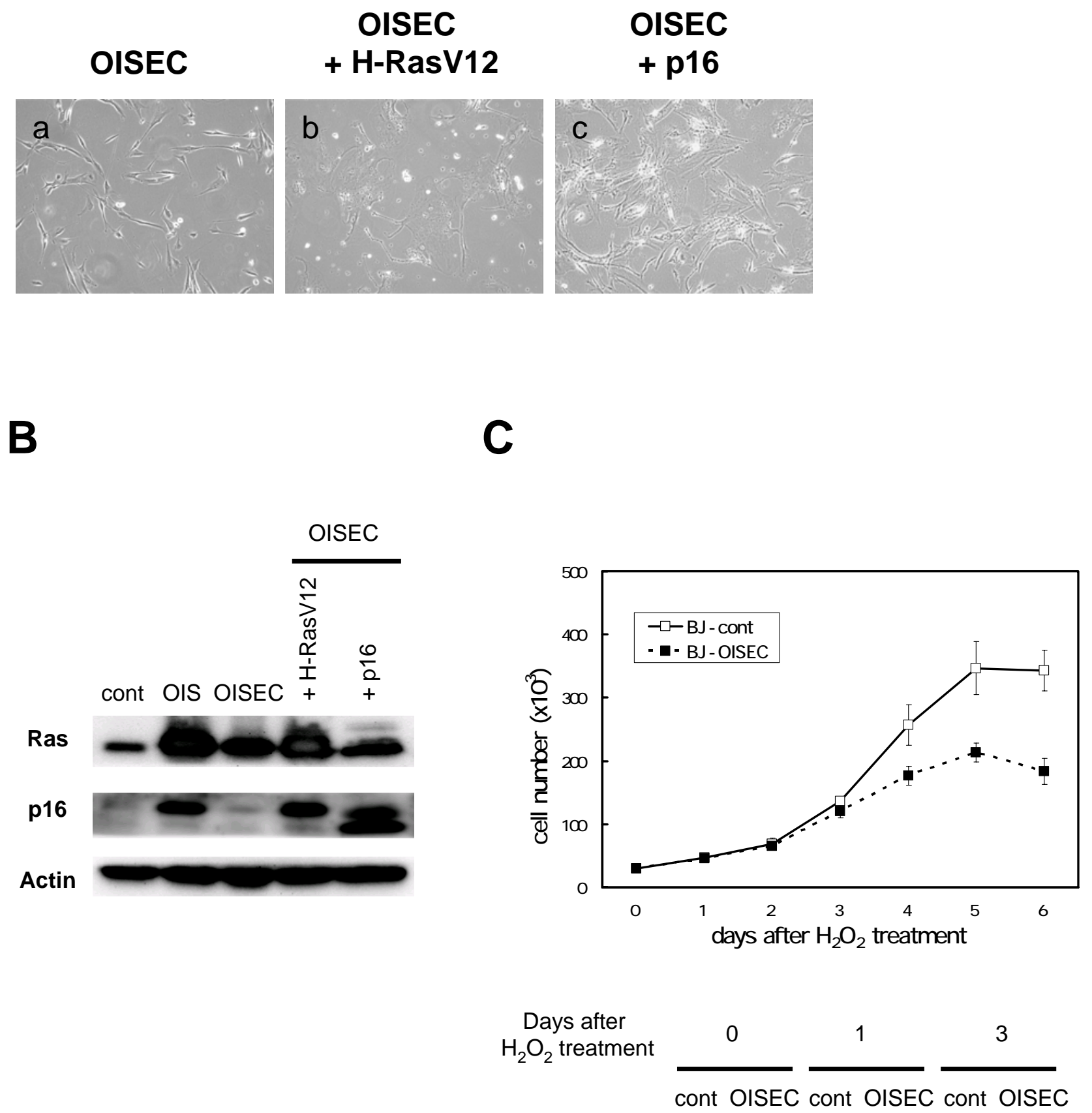

p16

Actin 
Fig. 3

A

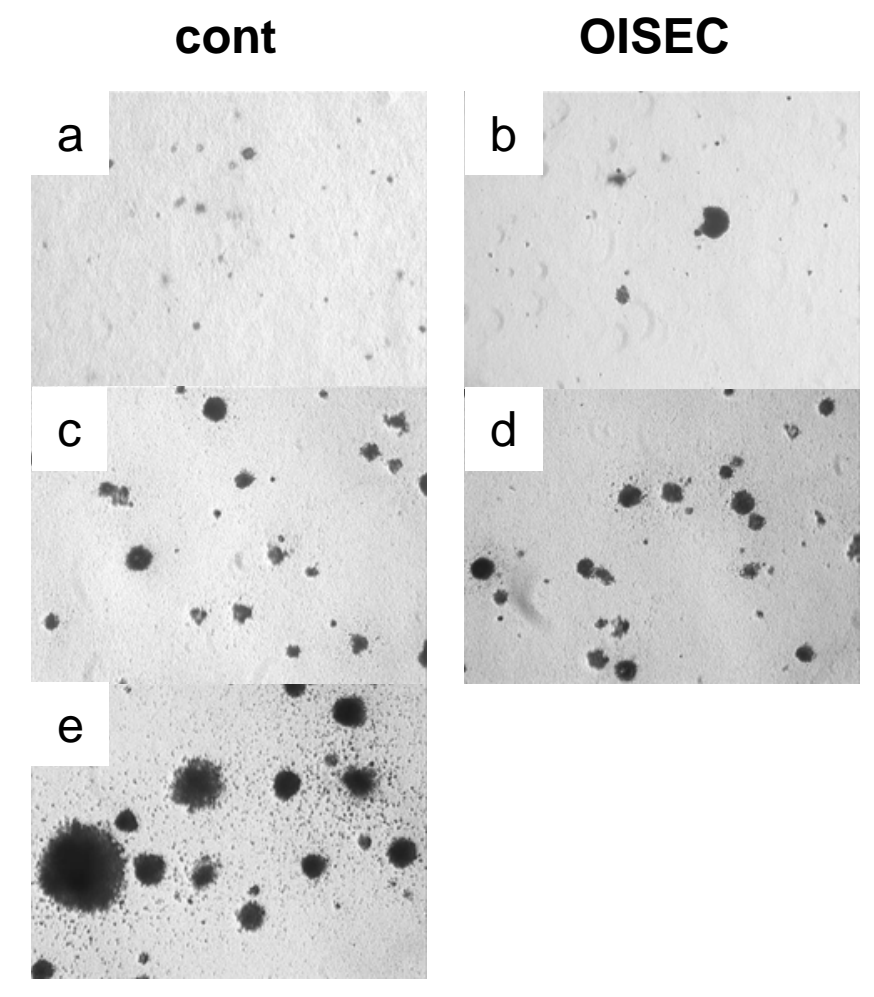

B

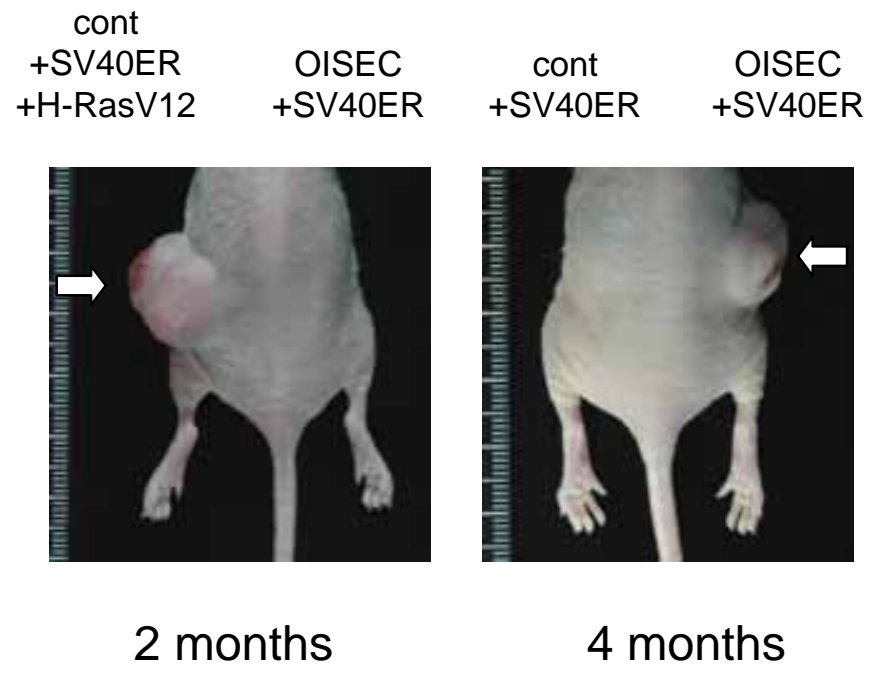


Fig. 3

C

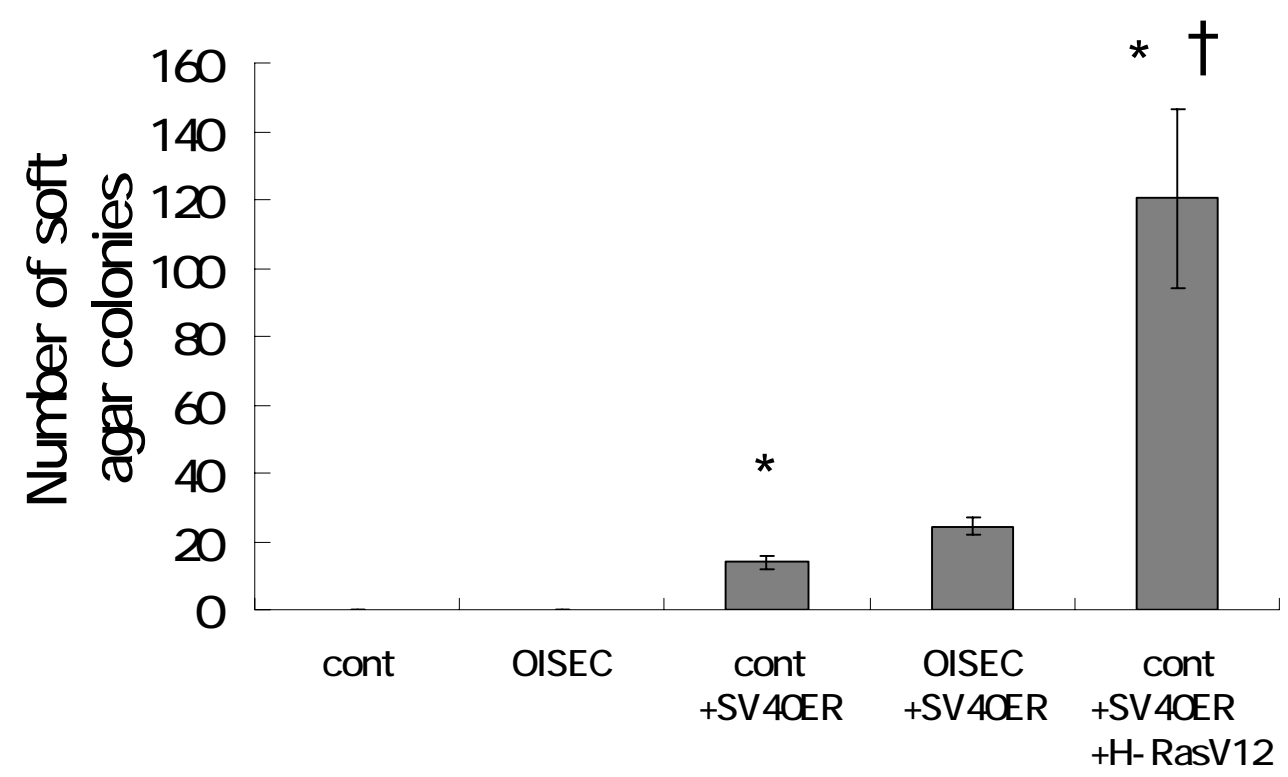

\begin{tabular}{|c|c|c|c|c|c|}
\hline $\begin{array}{c}\text { Tumor } \\
\text { Frequency }\end{array}$ & $\begin{array}{c}0 / 5 \\
\text { (4months) }\end{array}$ & $\begin{array}{c}0 / 5 \\
\text { (4months) }\end{array}$ & $\begin{array}{c}0 / 5 \\
\text { (4months) }\end{array}$ & $\begin{array}{c}3 / 5 \\
\text { (4months) }\end{array}$ & $\begin{array}{c}5 / 5 \\
\text { (2months) }\end{array}$ \\
\hline
\end{tabular}

D
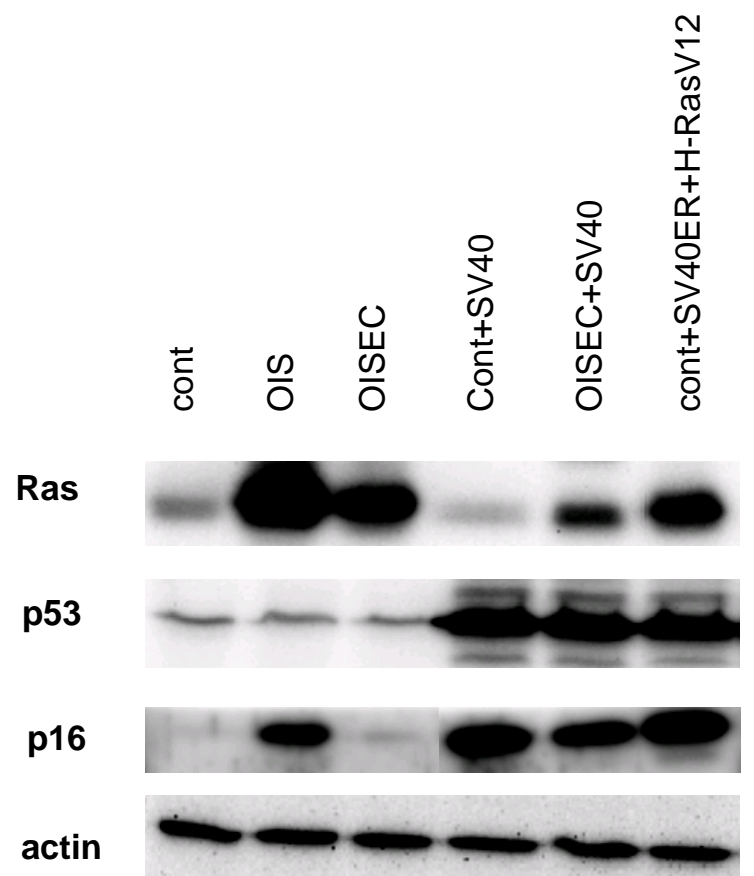
Fig. 4

A
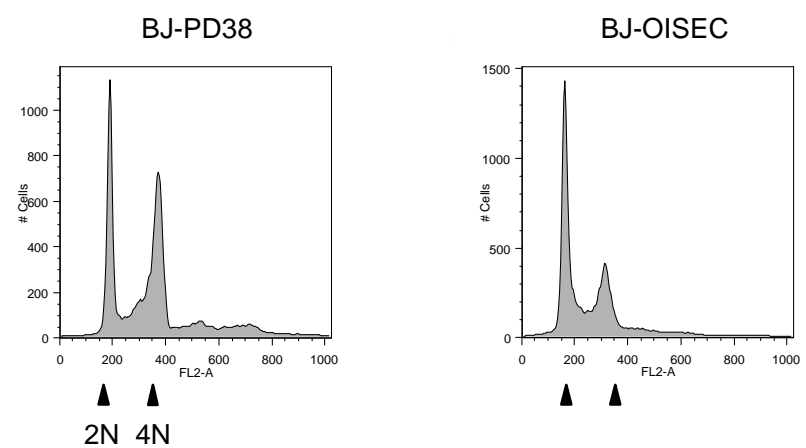

BJ-OISEC+SV40ER

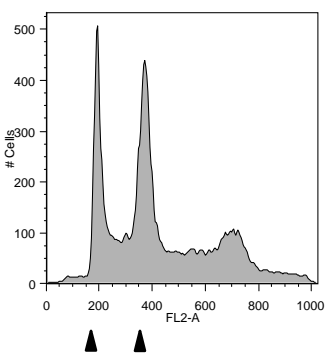

BJ-cont+SV40ER+H-RasV12

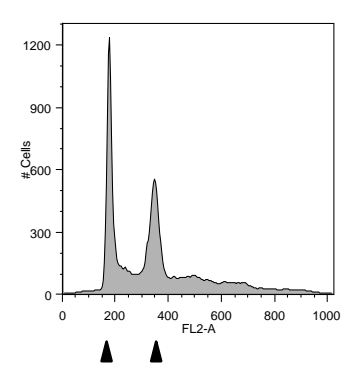

B
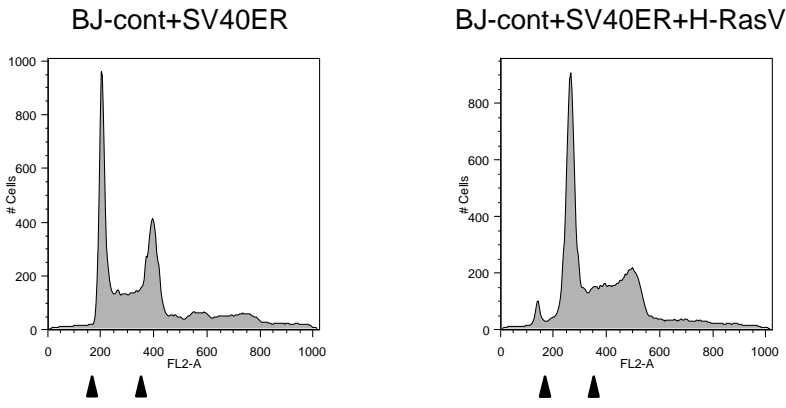

BJ-OISEC+SV40ER xenograft

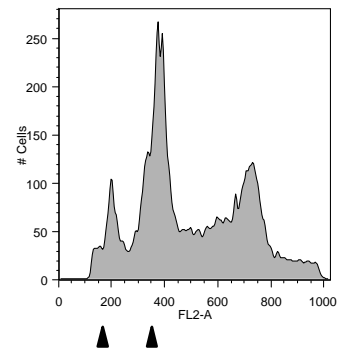

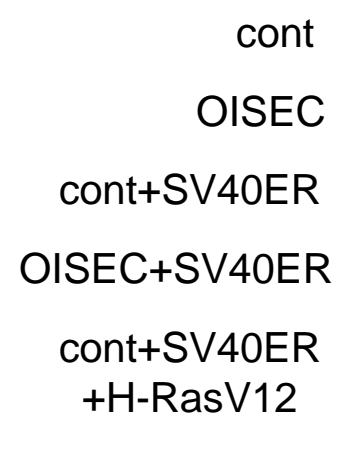

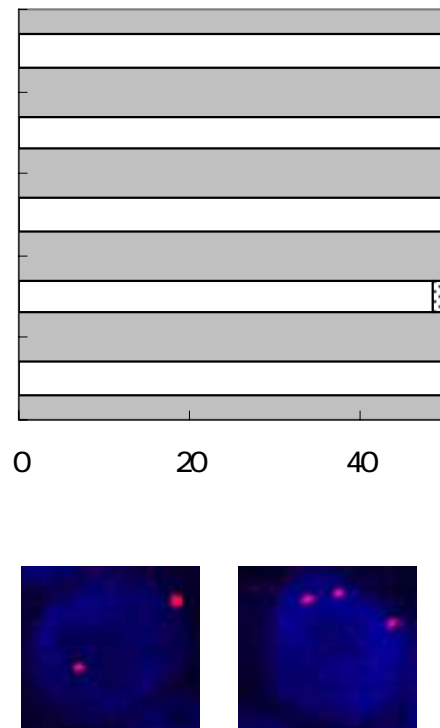

+1.

-

खें

$\square 2$

웅

圆 4

口5

copy number

60

80

100

$\%$
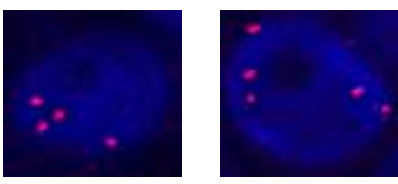
Fig. 4

C

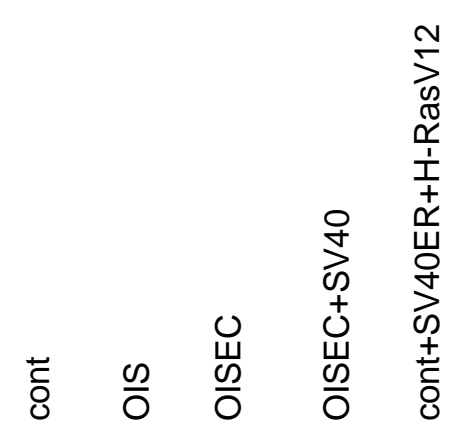

Nanog

Oct3/4

Sox2

GAPDH
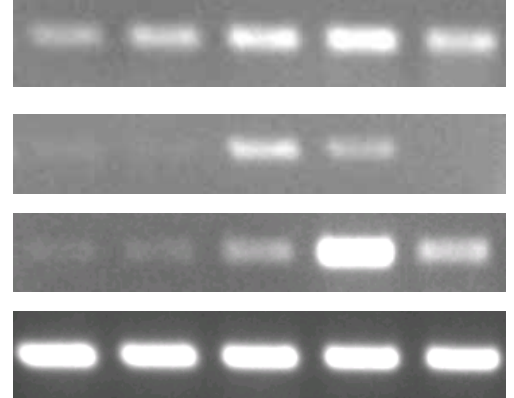

D

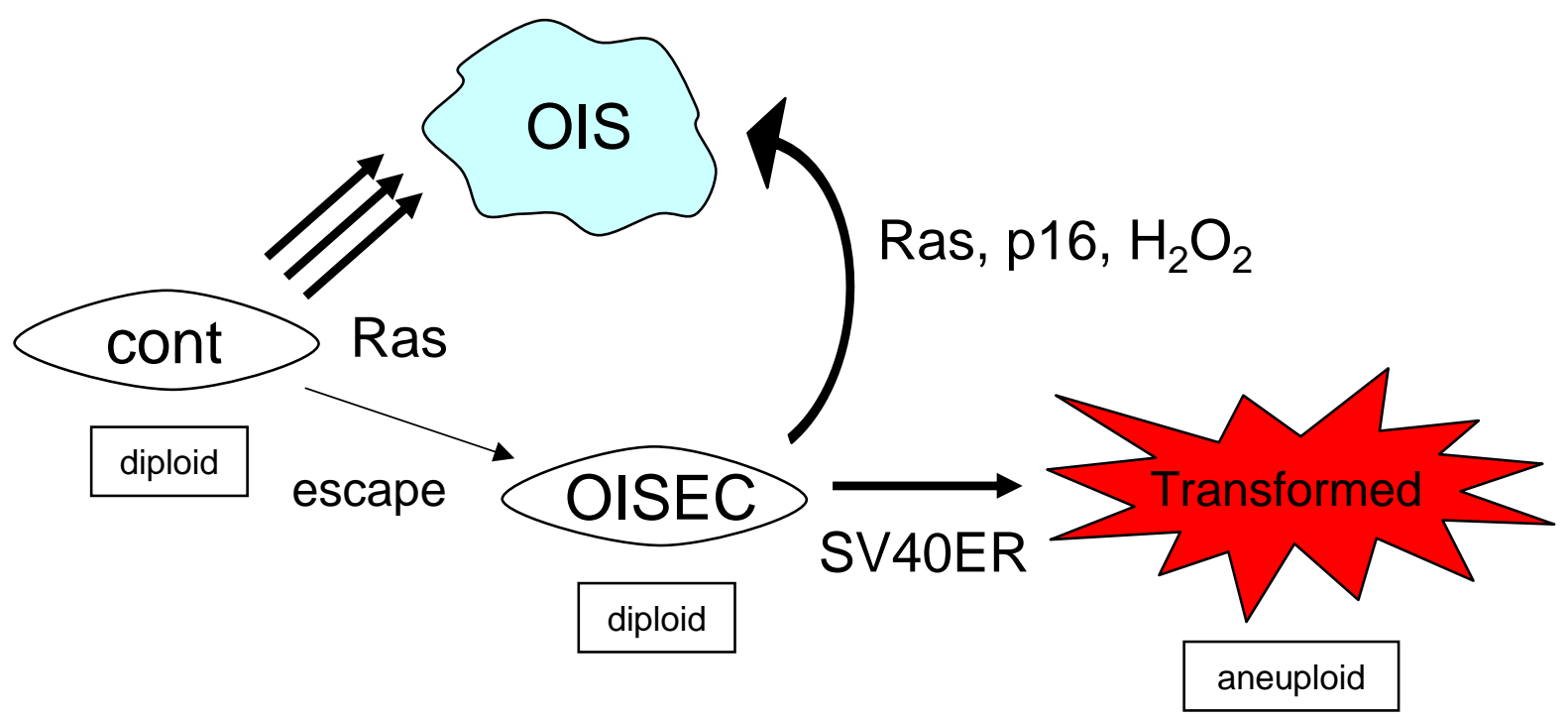

